\title{
Ropivacaine attenuates endotoxin plus hyperinflation-mediated acute lung injury via inhibition of early-onset Src-dependent signaling
}

Tobias Piegeler ${ }^{1,5}$, Randal O Dull1,2,3, Guochang Hu ${ }^{1,2}$, Maricela Castellon ${ }^{1,2}$, Andreia Z Chignalia', Ruben G Koshy ${ }^{1}$, E Gina Votta-Velis ${ }^{1,7}$, Alain Borgeat ${ }^{6}$, David E Schwartz' ${ }^{1}$, Beatrice Beck-Schimmer ${ }^{5}$ and Richard D Minshall ${ }^{1,2,3,4^{*}}$

\begin{abstract}
Background: Acute lung injury (ALI) is associated with high mortality due to the lack of effective therapeutic strategies. Mechanical ventilation itself can cause ventilator-induced lung injury. Pulmonary vascular barrier function, regulated in part by Src kinase-dependent phosphorylation of caveolin-1 and intercellular adhesion molecule-1 (ICAM-1), plays a crucial role in the development of protein-/neutrophil-rich pulmonary edema, the hallmark of ALI. Amide-linked local anesthetics, such as ropivacaine, have anti-inflammatory properties in experimental ALI. We hypothesized ropivacaine may attenuate inflammation in a "double-hit" model of ALI triggered by bacterial endotoxin plus hyperinflation via inhibition of Src-dependent signaling.
\end{abstract}

Methods: C57BL/6 (WT) and ICAM-1 ${ }^{-/-}$mice were exposed to either nebulized normal saline (NS) or lipopolysaccharide (LPS, $10 \mathrm{mg}$ ) for 1 hour. An intravenous bolus of $0.33 \mathrm{mg} / \mathrm{kg}$ ropivacaine or vehicle was followed by mechanical ventilation with normal $(7 \mathrm{ml} / \mathrm{kg}$, NTV) or high tidal volume $(28 \mathrm{ml} / \mathrm{kg}, \mathrm{HTV})$ for 2 hours. Measures of ALI (excess lung water (ELW), extravascular plasma equivalents, permeability index, myeloperoxidase activity) were assessed and lungs were homogenized for Western blot analysis of phosphorylated and total Src, ICAM-1 and caveolin-1. Additional experiments evaluated effects of ropivacaine on LPS-induced phosphorylation/expression of Src, ICAM-1 and caveolin-1 in human lung microvascular endothelial cells (HLMVEC).

Results: WT mice treated with LPS alone showed a 49\% increase in ELW compared to control animals ( $p=0.001)$, which was attenuated by ropivacaine $(p=0.001)$. HTV ventilation alone increased measures of ALI even more than LPS, an effect which was not altered by ropivacaine. LPS plus hyperinflation ("double-hit") increased all ALI parameters (ELW, EVPE, permeability index, MPO activity) by 3-4 fold compared to control, which were again decreased by ropivacaine. Western blot analyses of lung homogenates as well as HLMVEC treated in culture with LPS alone showed a reduction in Src activation/expression, as well as ICAM-1 expression and caveolin-1 phosphorylation. In $/ \mathrm{CAM}^{-1} 1^{-1-}$ mice, neither addition of LPS to HTV ventilation alone nor ropivacaine had an effect on the development of ALI.

Conclusions: Ropivacaine may be a promising therapeutic agent for treating the cause of pulmonary edema by blocking inflammatory Src signaling, ICAM-1 expression, leukocyte infiltration, and vascular hyperpermeability.

Keywords: Acute lung injury, ARDS, Ventilator-induced lung injury, Local anesthetics, Endothelium, Caveolin-1, Src protein tyrosine kinase

\footnotetext{
* Correspondence: rminsh@uic.edu

${ }^{1}$ Department of Anesthesiology, University of Illinois Hospital \& Health

Sciences System, 835 S. Wolcott Ave (m/c 868), Chicago, IL 60612, USA

${ }^{2}$ Department of Pharmacology, University of Illinois Hospital \& Health

Sciences System, Chicago, IL, USA

Full list of author information is available at the end of the article
} 


\section{Background}

Acute lung injury (ALI) and acute respiratory distress syndrome (ARDS) are associated with high morbidity and mortality $[1,2]$. Treatment options are largely supportive (e.g. lung-protective ventilation) [3] and thus there is a need for effective anti-inflammatory strategies that treat pulmonary endothelial hyperpermeability, a hallmark of the disease. Despite the necessity of mechanical ventilation in the supportive management of ALI or ARDS, ventilation per se can also contribute to lung injury (i.e., ventilator-induced lung injury, or VILI) [4]. Large tidal volumes, high inspiratory pressures, and/or high levels of positive end-expiratory pressure lead to a proteinand neutrophil-rich permeability-type pulmonary edema, similar to that occurring in ALI [5]. Experimental data also suggests that VILI is even more severe when induced in combination with bacterial endotoxin, as exemplified in the "double-hit" mouse model of ALI/VILI [6].

Local anesthetics are widely used in clinical practice for local, regional and neuraxial anesthesia, as well as for peri- and postoperative pain control $[7,8]$. In addition, they have also been demonstrated to exhibit significant anti-inflammatory properties [9-11]. In an earlier study of bacterial endotoxin-induced lung injury, it was shown that administration of the long-acting amide-linked local anesthetic ropivacaine attenuated endothelial cell NFkB activation and inflammatory lung injury in vivo and lung epithelial cell activation in vitro [9].

Src protein tyrosine kinase (Src) is known to regulate endothelial barrier function and to play a key role in mediating inflammatory vascular hyperpermeability in vitro [12]. Intercellular adhesion molecule-1 (ICAM-1), a cell surface molecule of the immunoglobulin superfamily, mediates firm adhesion of circulating neutrophils and thereby enhances their transmigration through the endothelial barrier. ICAM-1 is phosphorylated by Src on tyrosine 512 (human; tyrosine 518 in mice) [13,14] during pulmonary vascular inflammation and is thought to play an important role in the mechanism of ALI and ARDS [14-16]. Additionally, Src-dependent phosphorylation of caveolin-1 on tyrosine 14, which is known to promote the transcellular transport of albumin via caveolae [17] as well as regulate downstream signaling that can lead to disruption of adherens junctions [18], also contributes significantly to the development of ALI $[12,19,20]$.

In the present study, we hypothesized that the local anesthetic ropivacaine, at clinically relevant concentrations, may have anti-inflammatory properties by blocking endotoxin-induced Src signaling in mice and cultured human endothelial cells. We tested the hypothesis that ropivacaine attenuates lung injury/inflammatory hyperpermeability in the mouse induced by either high tidal volume (HTV) ventilation or bacterial endotoxin alone, versus the "double-hit" model of HTV ventilation together with bacterial endotoxin [6]. In these experiments, we assessed whether anti-inflammatory effects were mediated by reducing Src-dependent phosphorylation of ICAM-1 and caveolin-1 in endothelial cells, thereby blocking inflammatory hyper-permeability [12].

\section{Methods \\ Animals}

All animal experiments were approved by the University of Illinois Institutional Animal Care and Use Committee (IACUC). Mice were housed in the mouse barrier facility at UIC and were allowed full access to food and water until the time of the experiment. Two strains of mice were used in this study, wild-type C57BL/6 (WT) and strain-matched ICAM-1 knockout $\left(I C A M-1^{-/-}\right)$mice.

\section{Animal protocol}

To evaluate the effects of ropivacaine on acute lung injury as induced by high tidal volume ventilation or endotoxin, as well as by the "double-hit" with endotoxin and VILI, mice were exposed to either nebulized normal saline (NS, 0.9\% sodium chloride solution, Hospira, Lake Forest, IL) or $10 \mathrm{mg}$ nebulized Escherichia coli serotype 055:B5 lipopolysaccharide diluted in NS (LPS, Sigma-Aldrich, St. Louis, MO) for 1 hour. During the second hour of the protocol, anesthesia was induced via intraperitoneal injection of $100 \mathrm{mg} / \mathrm{kg}$ ketamine (Hospira) and $5 \mathrm{mg} / \mathrm{kg}$ xylazine (Lloyd Laboratories, Shenandoah, IA) and a PE10 catheter was inserted into the right internal jugular vein. Two hours after the start of the experiment, mice received a $30 \mu \mathrm{l}$ intravenous bolus of either NS or ropivacaine (R) at $1 \mathrm{mM}$ concentration (Naropin ${ }^{\circ}$, APP Pharmaceuticals, Schaumburg, IL) diluted in NS solution. The total amount of administered drug was therefore $0.01 \mathrm{mg}$, or $0.33 \mathrm{mg} / \mathrm{kg}$ in a $30 \mathrm{~g}$ mouse. Mice were then subjected to volumecontrolled mechanical ventilation via a tracheostomy with either a normal tidal volume of $7 \mathrm{ml} / \mathrm{kg}$ (NTV) or high tidal volume of $28 \mathrm{ml} / \mathrm{kg}$ (HTV) to induce VILI [21-23]. Mice were randomly assigned to one of eight groups $(n=7$ each) as shown in Figure 1: 1) Nebulized NS, intravenous NS, NTV ventilation (NS-NS-NTV; control), 2) NS-RNTV, 3) LPS-NS-NTV, 4) LPS-R-NTV, 5) NS-NS-HTV, 6) NS-R-HTV, 7) LPS-NS-HTV, 8) LPS-R-HTV. Mice were given an additional intraperitoneal ketamine/xylazine injection (half of initial dose) 1 hour after the initiation of mechanical ventilation to maintain anesthesia. Normothermia $\left(37^{\circ} \mathrm{C}\right.$ to $\left.38^{\circ} \mathrm{C}\right)$ was maintained using a heating lamp.

\section{Excess lung water (ELW), extravascular plasma equivalents (EVPE), permeability index}

One hour before the end of the experiment, mice received an intravenous injection of radioactive-labeled albumin ( $1 \mu \mathrm{C} \mathrm{I}^{125}$-albumin). At the end of the experiment, the body weight of the animal was determined and a blood 


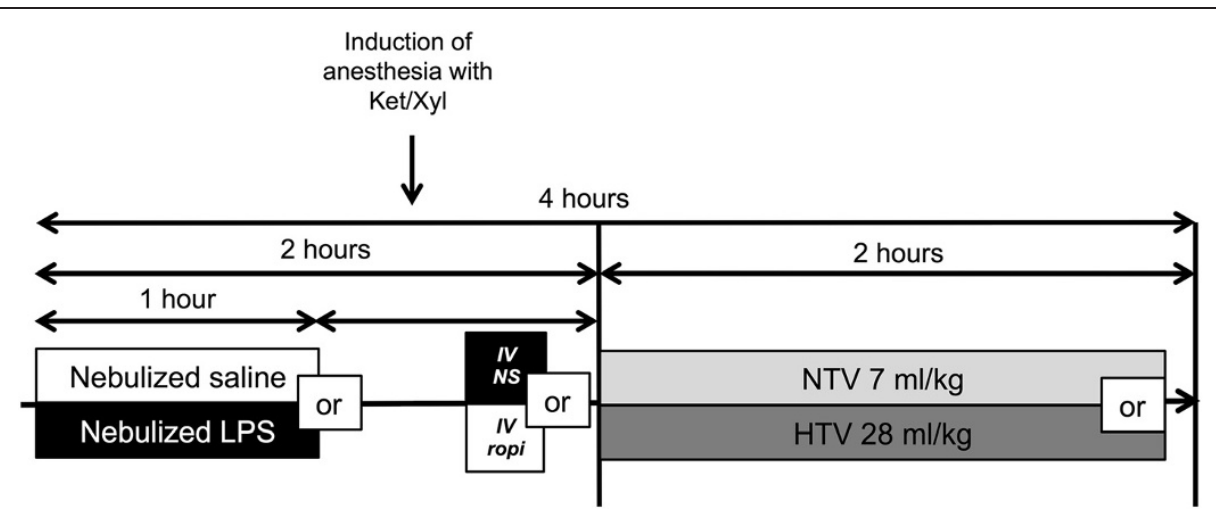

Figure 1 Schematic illustration of the workflow of animal experiments. C57BL/6 mice (WT) were exposed to either normal saline (NS) or nebulized LPS (10 mg) for 1 hour. Induction of anesthesia with ketamine/xylazine (Ket/Xyl) during the second hour of the experiment was followed by the insertion of a central venous catheter into the right or left internal jugular vein and the application of an intravenous bolus of either $0.01 \mathrm{mg}$ ropivacaine (ropi in the figure, $\mathrm{R}$ in the group description) or vehicle (normal saline, NS). Mice were then mechanically ventilated for 2 hours via a tracheostomy with either normal tidal volumes ( $7 \mathrm{ml} / \mathrm{kg}$, NTV) or high tidal volumes (28 $\mathrm{ml} / \mathrm{kg}$, HTV). Mice were randomized into 8 different groups ( $n=7$ each): 1) Nebulized NS, intravenous NS, NTV ventilation (NS-NS-NTV; control), 2) NS-R-NTV, 3) LPS-NS-NTV, 4) LPS-R-NTV, 5) NS-NS-HTV, 6) NS-R-HTV, 7) LPS-NS-HTV, 8) LPS-R-HTV.

sample was collected, either via a retro-orbital approach or by puncturing the inferior vena cava after opening up the abdominal cavity, and hematocrit was determined (IEC MB Centrifuge, Damon, Needham Heights, MA). An additional $400-500 \mu \mathrm{l}$ of blood was collected in tubes containing ethylenediaminetetraacetic acid (EDTA; BD Biosciences, Franklin Lakes, NJ). The lungs were then excised in total, placed into pre-weighed $5 \mathrm{ml}$ plastic tubes (BD Biosciences) and immediately covered to prevent evaporation. After initial weighing of the tube together with the lung, we added $1 \mathrm{ml}$ of ultrapure water and reweighed the containers. The lungs were then homogenized with a Kinematica Polytron homogenizer (Fisher Scientific, Pittsburgh, PA). A $0.25 \mathrm{ml}$ aliquot of lung homogenate was sedimented at $13000 \mathrm{rpm}$ for $10 \mathrm{~min}$ (Eppendorf 5415R microcentrifuge, Eppendorf, Hamburg, Germany). Hemoglobin concentration was measured in both the supernatant of the homogenate and the anti-coagulated whole blood sample with a $\mathrm{Hb} 201$ analyzer (Hemocue, Cypress, CA). Total lung homogenate ( $150 \mu \mathrm{l}$, before centrifugation), supernatant, and a whole blood sample were then put in pre-weighed aluminum dishes and weighed. The dishes were then placed in a drying oven $\left(60^{\circ} \mathrm{C}\right)$ for at least 24 hours, after which the dried samples were weighed again.

ELW was then calculated as described by Su et al. [24]:

First, we calculated the water fraction in the lung homogenate $\left(\mathrm{WF}_{\mathrm{h}}\right)$, the supernatant of the homogenate $\left(\mathrm{WF}_{\mathrm{s}}\right)$ and the whole blood sample $\left(\mathrm{WF}_{\mathrm{b}}\right)$ using the formula

$$
W F=\left(W_{w e t}-W_{d r y}\right) / W_{w e t},
$$

with $\mathrm{W}_{\text {wet }}$ representing the wet weight and $\mathrm{W}_{\text {dry }}$ being the dry weight.
We then calculated the blood volume found in the lung:

$$
Q_{b}=1.039 x\left(Q_{h} x W F_{h} x H b_{s}\right) /\left(W F_{s} x H b_{b}\right)
$$

The number of 1.039 is the density of blood, $\mathrm{Q}_{\mathrm{h}}$ denotes the lung homogenate weight (=whole lung wet weight + weight of ultrapure water), $\mathrm{Hb}_{\mathrm{s}}$ represents the hemoglobin concentration in the homogenate supernatant, and $\mathrm{Hb}_{\mathrm{b}}$ the hemoglobin concentration of the whole blood sample.

The calculation of the volume of water in the lung was executed with the following formula:

$$
Q_{w}=\left(Q_{h} x W F_{h}\right)-\left(Q_{b} x W F_{b}\right)-W_{w} .
$$

Here, $W_{w}$ represents the weight of the ultrapure water added before the homogenization of lung tissue (see above).

The calculation of the whole lung dry weight $\left(Q_{d}\right)$ was also necessary:

$$
Q_{d}=\text { whole lung wet weight }-Q_{w}-Q_{b}
$$

Finally, ELW was calculated as follows:

$$
\begin{aligned}
E L W= & \left\{\left(Q_{w \exp } / Q_{d \exp } x Q_{d e x p}\right) \times\left(Q_{w \text { controll }} / Q_{d \text { control } x} Q_{d \text { control }}\right)\right\} \\
& x 1000(\mu l) .
\end{aligned}
$$

$\mathrm{Q}_{\mathrm{w} \text { exp }}$ is the volume of water found in the lung of experimental animals and $\mathrm{Q}_{\mathrm{d} \text { exp }}$ is the dry weight of the lung in the experimental animals. Mice of the same age as the experimental groups served as controls.

For EVPE, we additionally assessed radioactivity of both $100 \mu \mathrm{l}$ whole blood and the whole lung immersed in $1 \mathrm{ml}$ of water before homogenization in a $\gamma$-counter chamber (Perkin Elmer, Waltham, MA). Measured counts per 
minute were then normalized per gram (cpg) and used in the formula to determine EVPE as follows:

$$
E V P E=[\text { blood free lung tissue cpg /(plasma cpg } \times 1000)] .
$$

For the calculation of the endothelial permeability index, we first calculated the plasma volume:

Plasma Volume $=[($ body weight $) \times(1-$ Hematocrit $) \times 0.007 \times 1000]$.

The results from this calculation were used to determine the permeability index:

$$
\begin{aligned}
\text { Endothelial permeability }= & {[\text { blood }- \text { free lung tissue cpg }} \\
& /(\text { plasma cpg } x \text { plasma volume })] \\
& \times 100(\%) .
\end{aligned}
$$

\section{Myeloperoxidase activity}

Myeloperoxidase (MPO) activity in lung homogenates was used as a surrogate marker of neutrophil extravasation and sequestration as previously described $[6,25]$.

\section{Lung homogenates for Western blot analysis}

Whole lungs of animals from the different treatment groups were removed at the end of the experiment, immediately snap-frozen in liquid nitrogen, and stored at $-80^{\circ} \mathrm{C}$ until further processing. Equal lung parts were then immersed in lysis buffer $(0.4 \mathrm{M}$ Tris- $\mathrm{HCl} \mathrm{pH} \mathrm{7.5,} \mathrm{0.14} \mathrm{M}$ $\mathrm{NaCl}, 1.5 \%$ Triton X-100, $0.5 \%$ desoxycholic acid, $0.1 \%$ sodium dodecyl sulfate, protease inhibitor cocktail, $200 \mathrm{mM}$ phenylmethylsulfonylfluoride, $1 \mathrm{mM}$ EDTA, $1 \mathrm{mM}$ sodium-fluoride, and $1 \mathrm{mM}$ sodium-orthovanadate) and homogenized on ice. After a 30-minute incubation to allow protein dissociation, the homogenates were centrifuged for 20 minutes at 16,000 rpm to remove debris. The supernatant was collected and stored at $-80^{\circ} \mathrm{C}$ until further use.

\section{Cell cultures and in vitro experimental procedures}

Human lung microvascular endothelial cells (HLMVEC, Lonza, Walkersville, MD) were cultured in VascuLife Basal medium supplemented with the VascuLife VEGF-Mv LifeFactors kit (both from LifeLine Cell Technology, Frederick, $\mathrm{MD}$ ) containing $5 \%$ fetal bovine serum, $10 \mathrm{mM}$ L-glutamine, $5 \mathrm{ng} / \mathrm{ml}$ recombinant human ( $\mathrm{rh}$ ) vascular endothelial growth factor (VEGF), $5 \mathrm{ng} / \mathrm{ml}$ rh epidermal growth factor (EGF), $5 \mathrm{ng} / \mathrm{ml}$ rh fibroblast growth factor (FGF), $15 \mathrm{ng} / \mathrm{ml}$ rh insulin-like growth factor 1 (IGF-1), $1 \mu \mathrm{g} / \mathrm{ml}$ hydrocortisone hemisuccinate, $0.75 \mathrm{U} / \mathrm{ml}$ heparin, and $50 \mu \mathrm{g} / \mathrm{ml}$ ascorbic acid. All cell culture dishes, plates and flasks were coated with $0.2 \%$ gelatin (Sigma-Aldrich, St. Louis, MO) diluted in Dulbecco's phosphate buffered saline without calcium and magnesium (Cellgro, Manassas, VA). Experiments were performed in $90-100 \%$ confluent cells from passages $5-12$. Before the experiments, cells were grown in VascuLife Basal Medium without supplements for 16 hours. Cells were kept in $5 \% \mathrm{CO}_{2}$ and $95 \%$ room air in a water-jacketed incubator at $37^{\circ} \mathrm{C}$.

HLMVEC monolayers were incubated with Escherichia coli serotype 055:B5 lipopolysaccharide (LPS, SigmaAldrich, St. Louis, MO) at a concentration of $4 \mu \mathrm{g} / \mathrm{ml}$ diluted in VascuLife Basal Medium for 4 hours. Ropivacaine $0.5 \%$ was also diluted in VascuLife Basal Medium in order to be able to test several concentrations of the drug ( $1 \mathrm{nM}, 1 \mu \mathrm{M}, 10 \mu \mathrm{M}, 100 \mu \mathrm{M})$ in the absence or presence of LPS. For some experiments, cells were pretreated for 30 minutes with the Src kinase inhibitor 4-amino-5(4-chlorophenyl)-7-(dimethylethyl)pyrazolo[3,4- $d$ ] pyrimidine (PP2; $10 \mu \mathrm{M})$ dissolved in dimethylsulfoxide (DMSO, Sigma-Aldrich) or with DMSO alone as the vehicle control $(0.1 \%)$ prior to addition of LPS.

\section{Cell harvest and lysis}

At the end of the experiment, HLMVEC were harvested and lysed with radio-immunoprecipitation buffer (Boston Bioproducts, Ashland, MA), supplemented with protease inhibitor cocktail, $200 \mathrm{mM}$ phenylmethylsulfonylfluoride, $1 \mathrm{mM}$ EDTA, $1 \mathrm{mM}$ sodium-fluoride, and $1 \mathrm{mM}$ sodiumorthovanadate (all from Sigma-Aldrich) as previously described [26,27].

\section{Determination of total protein concentration}

Total protein concentration of lung homogenates and whole cell lysates was measured by DC Protein Assay Kit (BioRad, Hercules, CA) according to the manufacturer's instructions; immunoglobulin $\mathrm{G}$ was used for determination of the standard curve.

\section{Western blot}

Western blot analysis of either lung homogenates or whole cell lysates was carried out as previously described [26,27]. Antibodies against pY419 Src and total Src were purchased from Cell Signaling Technologies (Danvers, MA), for pY512 ICAM-1 and total ICAM-1 from Santa Cruz Biotechnology (Santa Cruz, CA), and for pY14 caveolin-1, total caveolin-1, and $\beta$-actin from BD Biosciences (Franklin Lakes, NJ).

\section{Statistical analysis}

First, normal distribution was assessed using a ShapiroWilk test. Normally distributed data was then subject to analysis by ANOVA followed by Bonferroni post-hoc testing to maintain the family-wise error rate $<0.05$. Not-normally distributed data was analyzed with non-parametric testing methods (Kruskal-Wallis and Mann-Whitney U tests) with Dunn's post-hoc correction. The in vivo measures of ALI (ELW, EVPE, Permeability, MPO activity) were compared as two separate sets of data: one between the groups 
that were subject to NTV ventilation and one between the groups that had received HTV ventilation. In both cases, the NS-NS-NTV group served as the control group. Experimental data are presented as mean \pm standard deviation (SD). All tests were performed two-sided and non-blinded with GraphPad Prism for Mac, Version 6 (GraphPad Software, La Jolla, CA). A $p$-value of $<0.05$ was considered to be statistically significant.

\section{Results}

Ropivacaine attenuates measures of ALI triggered by bacterial endotoxin and hyperinflation

To assess the influence of ropivacaine administration on the degree of ALI induced by endotoxin or HTV alone vs the "double-hit" model (see Figure 1), we measured ELW, EVPE and permeability index. Additionally, the activity of neutrophil MPO in lung homogenates was evaluated as an index of lung inflammation.

Treatment with LPS alone (LPS-NS-NTV) led to a $49 \%$ increase in ELW compared to control animals (NS-NSNTV; $p=0.001$, Figure 2A) which was significantly attenuated by ropivacaine (LPS-R-NTV group; $p=0.001$ ). However, WT animals ventilated with HTV (NS-NS-HTV) also showed a significant increase in ELW compared to control animals (NS-NS-NTV; $p=0.005$ ), however this effect was not altered by ropivacaine (NS-R-HTV group; $p=1)$. If mice were exposed to LPS prior to mechanical ventilation with HTV (LPS-NS-HTV), we observed a 2-fold increase in ELW compared to HTV alone (NS-NSHTV; $p<0.001)$ and a 3.5-fold increase compared to control (NS-NS-NTV; $p<0.001$ ). Ropivacaine (LPS-R-HTV group) significantly decreased the "double-hit" inflammatory response by $28 \%$ ( $p=0.001$; Figure $2 \mathrm{~A})$.

To further evaluate the effect of HTV ventilation, LPS, and ropivacaine on endothelial barrier function, changes in EVPE (Figure 2B) and permeability index were assessed (Figure 2C). These measures, which are based on the accumulation of radioactive ${ }^{125} \mathrm{I}$-albumin in the lungs, quantitatively assess endothelial barrier function in vivo during ALI. The two parameters showed patterns similar to that of ELW, except for the fact that there were no significant differences between the groups which were subject to NTV ventilation ( $p=0.091$ for EVPE; $p=0.113$ for permeability, Figures $2 \mathrm{~B}$ and $2 \mathrm{C}$ ). HTV ventilation, on the other hand, induced a significant increase in EVPE and permeability compared to control WT mice ( $p=0.006$ for EVPE; $p=0.035$ for permeability) and neither were altered by ropivacaine ( $p=1$ for both comparisons). LPS exposure
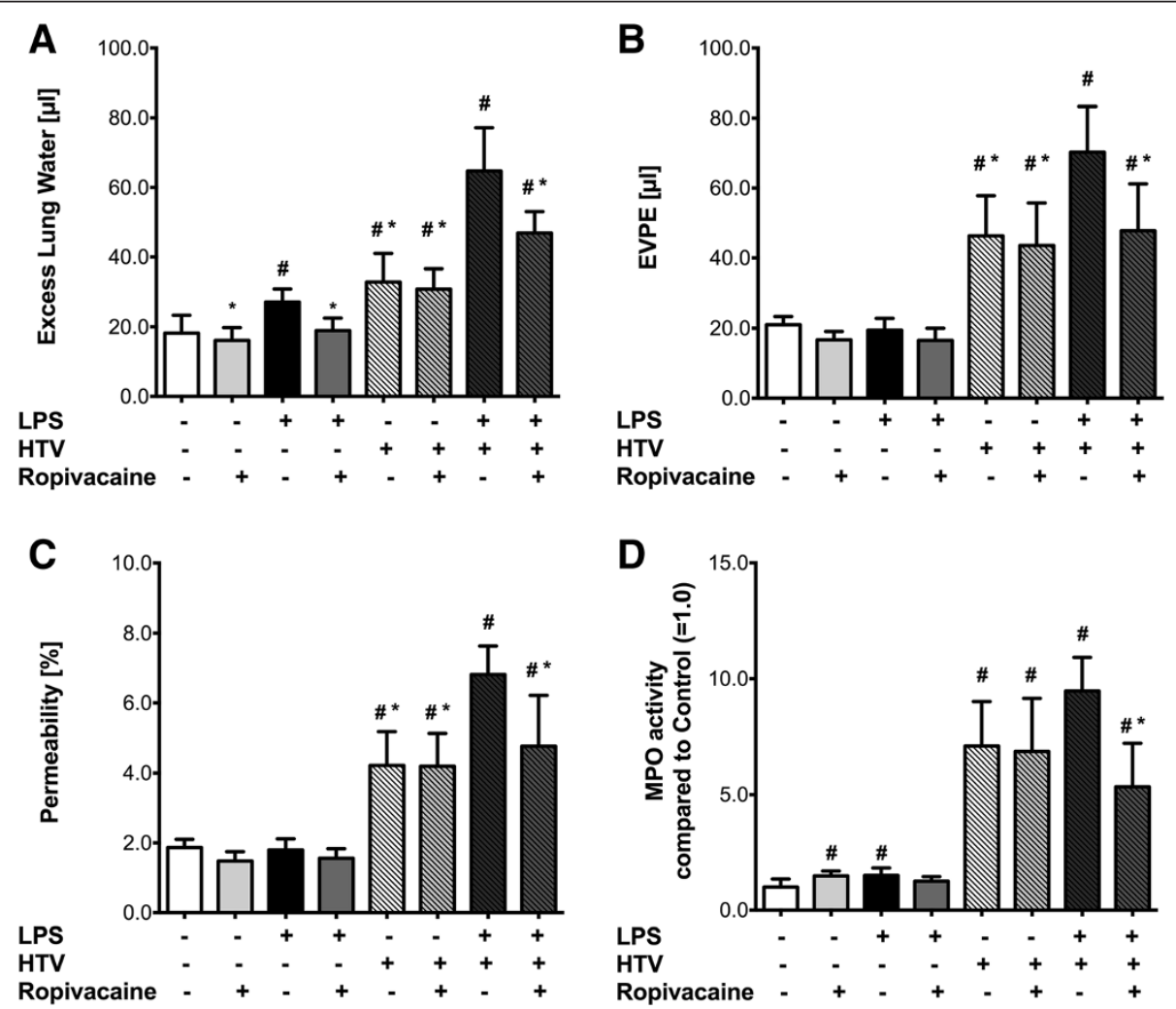

Figure 2 Effect of ropivacaine on acute lung injury. Acute lung injury was induced by either hyperinflation (HTV), bacterial lipopolysaccharide (LPS), or a combination of the two ("double-hit" model) in C57BL/6 wild type (C57 WT) mice. ALI was assessed by measuring (A) Excess lung water (ELW), (B) extravascular plasma equivalents (EVPE), (C) permeability index, and (D) myeloperoxidase activity as described in Methods. Values shown are mean \pm SD $(n=7) ;{ }^{*} p<0.05$ vs. control (NS-NS-HTV); ${ }^{*} p<0.05$ vs. LPS-NS-HTV. 
prior to HTV ventilation significantly increased EVPE and permeability index compared to control $(p<0.001$ for EVPE and permeability) and HTV ventilation alone ( $p=0.017$ for EVPE; $p=0.004$ for permeability), and this LPS-induced increase was attenuated significantly by ropivacaine $(p=0.039$ for EVPE; $p=0.042$ for permeability).

To assess the amount of neutrophil transmigration into the interstitial and alveolar spaces, MPO activity in lung homogenates was measured. Here, both LPS and ropivacaine led to a slight increase in MPO activity compared to control in mice that were subsequently ventilated with NTV ( $p=0.02$ for LPS-R-NTV, $p=0.027$ for NS-R-NTV, Figure 2D). However, there was no difference in MPO activity between control animals and those exposed to LPS and ropivacaine followed by NTV ventilation $(p=0.692)$. After HTV ventilation alone, there was a 7-fold increase in MPO activity compared to control $(p=0.001$; Figure 2D) which was not affected by ropivacaine (NS-R-HTV group; $p=1$ ). LPS exposure before HTV ventilation increased MPO activity even more (9-fold over control; $p<0.001$ ), which was significantly reduced in mice treated with ropivacaine $(p=0.013$; Figure 2D).

\section{Effect of ropivacaine on Src, ICAM-1 and caveolin-1 in lung homogenates of mice challenged with endotoxin alone}

In order to investigate the anti-inflammatory mechanism by which ropivacaine reduced edema formation (ELW) in mice following treatment with aerosolized LPS, we measured the phosphorylation status and expression levels of Src (Figure 3A), ICAM-1 (Figure 3B) and caveolin-1 (Figure $3 \mathrm{C}$ ) via Western blot analysis. Src activation, expressed as the ratio of Src, phosphorylated at tyrosine 418, over total Src (Figure 3Aii) was on average 2-fold higher in lungs treated with LPS alone as compared to control animals, however, this effect did not reach statistical significance $(\mathrm{n}=5, p=1)$. Treatment with ropivacaine together with LPS significantly decreased Src activation compared to treatment with LPS alone $(p=0.018)$. There were no differences in Src expression between the groups subjected to NTV ventilation ( $p=0.64$, Figure 3Aiii).

Similar results were obtained for the expression and phosphorylation of ICAM-1 at tyrosine 518, expressed as a ratio of the phosphorylated protein over the total amount of ICAM-1. Expression levels were not altered by any of the treatments prior to NTV ventilation ( $p=0.451$, Figure 3Biii), but there was a non-significant increase of $80 \%$ in ICAM-1 phosphorylation after exposure to LPS compared to control $(p=0.325)$ which was completely abolished by ropivacaine ( $p=0.018$, Figure 3Bii).

No significant changes in either caveolin-1 phosphorylation (expressed as the ratio of caveolin-1, phosphorylated at tyrosine 14 over the total amount of caveolin-1,
Figure 3Cii, $p=0.466$ ) or expression ( $p=0.874$, Figure 3Ciii) were detected (Figures $3 \mathrm{Cii}$ and $3 \mathrm{Ciii})$.

\section{Effect of ropivacaine on Src, ICAM-1 and caveolin-1 in lung homogenates of mice challenged with both endotoxin and hyperinflation}

To assess the anti-inflammatory mechanism of ropivacaine in the "double-hit" mouse model of ALI, we again measured the phosphorylation status and expression levels of Src, ICAM-1 and caveolin-1 via Western blot analysis in lung homogenates of WT mice treated with HTV ventilation +/- LPS and +/- ropivacaine as described above (representative blots shown in Figures 4Ai, 4Bi and 4Ci). Densitometry analysis $(n=12-14)$ showed no significant changes in Src activation at the 4 hour time point after HTV alone (Figure 4Aii) compared to control $(p=1)$. The application of ropivacaine before HTV ventilation reduced Src-pTyr ${ }^{418} /$ Src by $37 \%$ compared to HTV alone, however, this effect was not statistically significant $(p=0.678)$. Src expression in lung homogenates (Figure 4Aiii) doubled in both the NS-NS-HTV and the LPS-NS-HTV groups compared to control ( $p=0.024$ and $p=0.045$, respectively). In both settings - with or without LPS - the addition of ropivacaine completely abolished the observed increase in Src expression ( $p=0.012$ for NS-R-HTV and $p=0.026$ for LPS-R-HTV; Figure 4Aiii). Similar results were obtained for ICAM-1 phosphorylation (Figure 4Bii); neither HTV ventilation alone nor LPS plus HTV were different from control ( $p=1$ for both comparisons).

Lung tissue ICAM-1 expression (Figure 4Biii), however, increased by $259 \%$ compared to control following HTV ventilation $(p=0.006)$ and this increase was completely blocked by ropivacaine $(p=0.004)$. LPS plus HTV ventilation increased ICAM-1 expression to about the same extent as HTV ventilation alone (LPS-NSHTV, $p=0.001$ vs. control), which again was reduced by $73 \%$ in mice treated with ropivacaine (LPS-R-HTV, $p=0.04)$.

Whereas no effect of ropivacaine was observed on Src and ICAM-1 phosphorylation, caveolin-1 phosphorylation at tyrosine 14 could be blocked by ropivacaine (Figure 4Cii). Ropivacaine plus subsequent HTV ventilation (NS-R-HTV) decreased Cav-1-pTyr ${ }^{14} / \mathrm{Cav}-1$ by $51 \%$ compared to HTV ventilation alone $(p<0.001)$, and in addition, blocked LPS/HTV-induced increase in Cav-1 phosphorylation ( $p<0.001$; Figure $4 \mathrm{Cii})$. The expression of caveolin-1 (Cav-1) did not change in any of the treatment groups ( $p=0.501$, Figure 4Ciii).

\section{Requirement of ICAM-1 in mediating acute lung injury in the double-hit mouse model}

To further characterize the mechanism of the antiinflammatory effect of ropivacaine in the double-hit mouse model of ALI, additional experiments in 


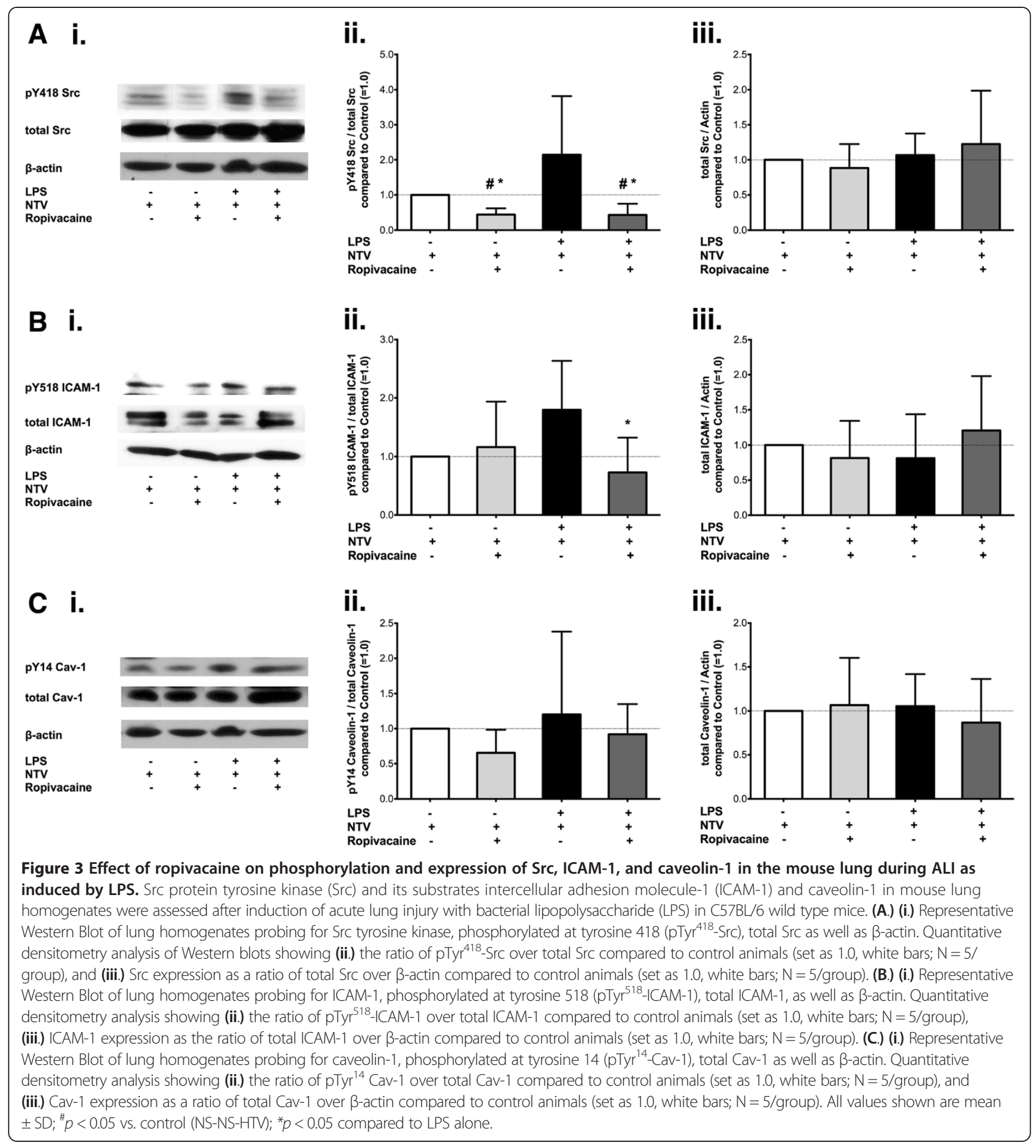

$I C A M-1^{-/-}$mice using the same procedures as described for WT animals were performed. As shown in Figure 5A-D, a significant increase in all measures of ALI (ELW, EVPE, permeability, and MPO activity) induced by HTV ventilation alone in $I C A M-1^{-/-}$mice was observed. However, unlike that which was noted in WT mice, LPS did not further increase lung inflammation or permeability, and interestingly, ropivacaine had no effect in $I C A M-1^{-/-}$mice. As there was no significant effect of ropivacaine on ALI in $I C A M-1^{-/-}$mice, Western blot analyses of the lungs of these animals were not performed. 


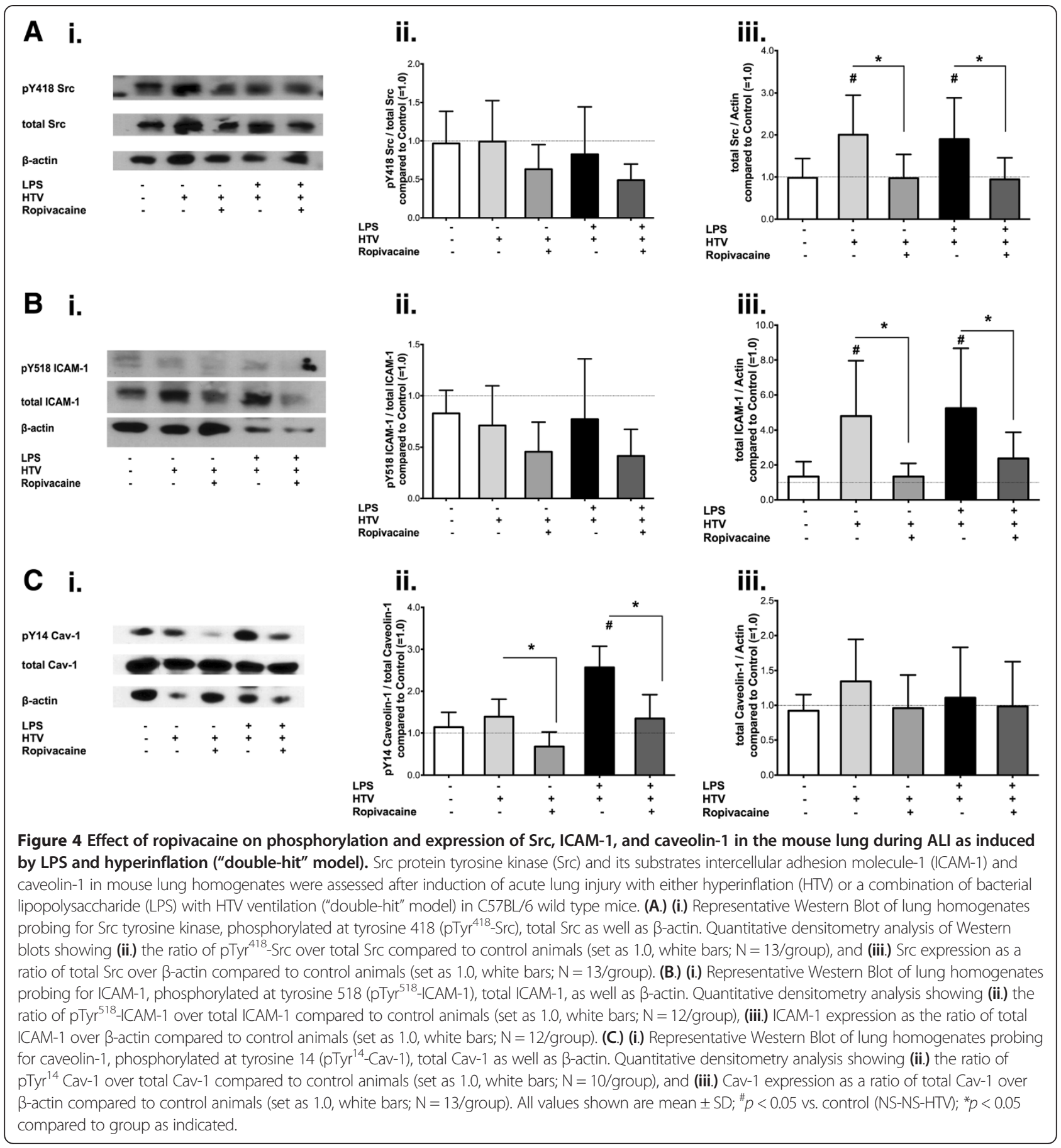

Effect of ropivacaine on endotoxin-induced changes in expression/phosphorylation of Src, ICAM-1 and caveolin-1 in cultured human lung microvascular endothelial cells (HLMVECS)

\section{Ropivacaine blocks LPS-induced Src activation and} expression in HLMVECS

To determine whether the anti-inflammatory and barrier protective effects of ropivacaine observed in LPS-treated
WT mouse lungs were due to direct effects of ropivacaine on the endothelium, HLMVEC were incubated with LPS at a concentration of $4 \mu \mathrm{g} / \mathrm{ml}$ for 4 hours in presence or absence of ropivacaine at a concentration of $1 \mathrm{nM}\left(10^{-9} \mathrm{M}\right)$. Analysis of whole cell lysates was conducted via Western blot, probing for $\mathrm{pTyr}^{419}$ Src, total Src, and $\beta$-actin (Figure 6Ai). These studies showed that LPS-induced increase in Src activity $(69 \%, p=0.022$; Figure 6Aii) and 

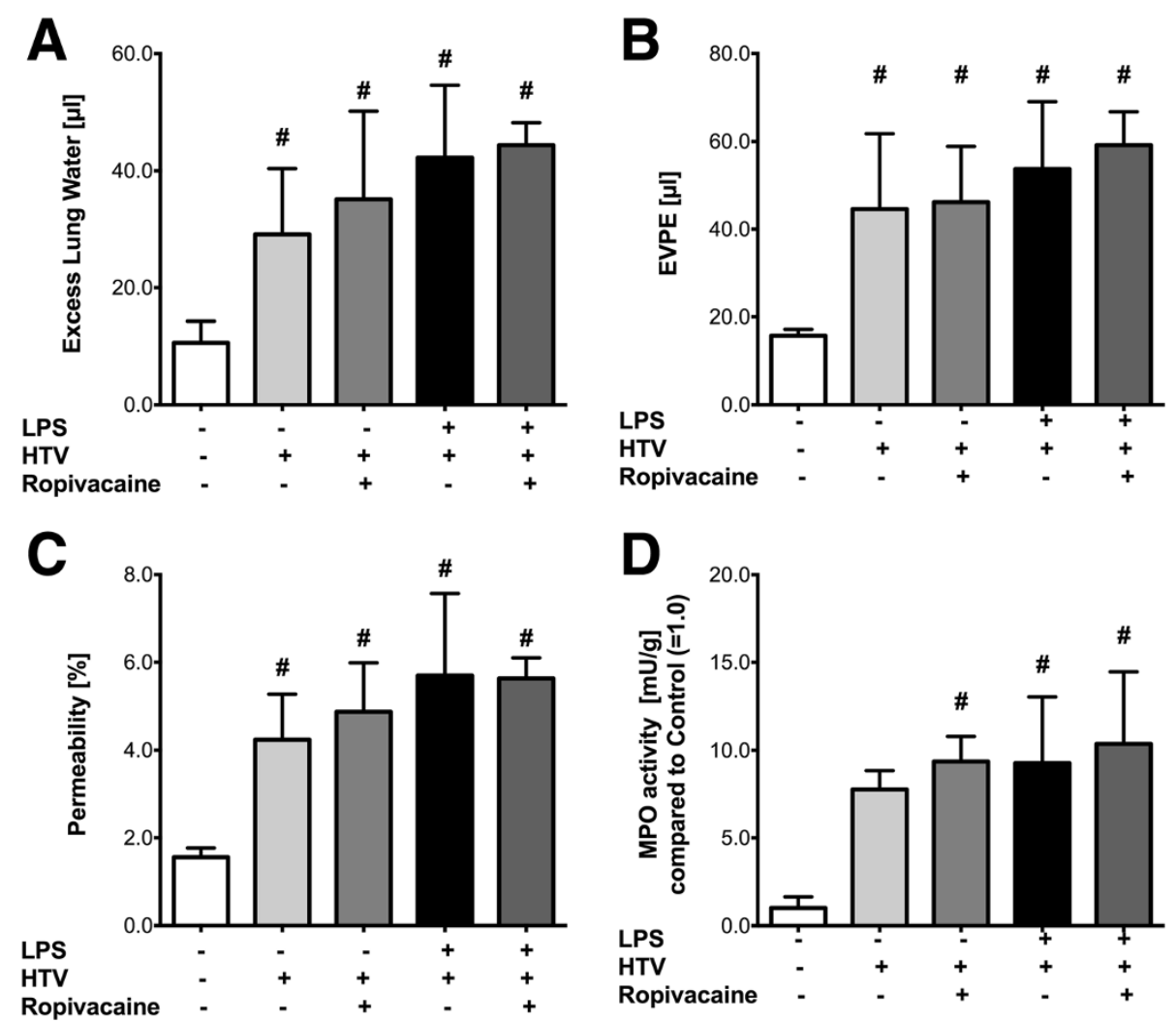

Figure 5 Effect of ropivacaine on acute lung injury in ICAM-1 ${ }^{-/}$mice. ALI, induced by either hyperinflation (HTV), bacterial lipopolysaccharide (LPS), or a combination of the two ("double-hit" model) in ICAM-1 $1^{-1-}$ mice, was assessed by measuring (A) excess lung water (ELW), (B) extravascular plasma equivalents (EVPE), (C) permeability index, and (D) myeloperoxidase activity as described in Methods. Values shown are mean \pm SD with $n=7$, except for MPO activity $(n=3) .{ }^{\#} p<0.05$ vs. control (NS-NS-HTV); ${ }^{*} p<0.05$ vs. LPS-NS-HTV.

expression (71\%, $p=0.019$, Figure 6Aiii) were completely blocked by $1 \mathrm{nM}$ ropivacaine ( $p=0.001$ for Src activation, Figure 6Aii; $p<0.001$ for Src expression, Figure 6Aiii).

\section{Ropivacaine attenuates LPS-induced ICAM-1 expression in HLMVEC}

The same whole cell lysates analyzed via Western Blot for c-Src $(\sim 60 \mathrm{kDa})$ were also analyzed for human ICAM-1 $(\sim 120 \mathrm{kDa})$, phosphorylated at tyrosine 512 (pTyr $^{512}$ ICAM-1), total ICAM-1, and $\beta$-actin (Figure 6Bi). ICAM-1 phosphorylation in HLMVEC was not significantly altered by LPS compared to control $(p=0.181$, Figure 6Bii), whereas ICAM-1 expression increased by $144 \%$ after incubation with LPS ( $p=0.004$, Figure 6Biii) and this increase was significantly attenuated in cells co-incubated with ropivacaine ( $1 \mathrm{nM}, p=0.028)$.

\section{Ropivacaine blocks LPS-induced Src-dependent caveolin-1 phosphorylation}

HLMVEC lysates incubated with LPS in presence or absence of different concentrations of ropivacaine were analyzed by Western blot, focusing on phosphorylated Cav-1 $\left(\mathrm{pTyr}^{14}-\mathrm{Cav}-1\right)$, one of the primary substrates of Src, as well as the total amount of Cav-1 and $\beta$-actin (Figure 6 Ci). LPS-induced increase in $\mathrm{pTyr}^{14}$-Cav-1 (132\% of untreated cells; $p<0.001)$ was completely abolished by 1 $\mathrm{nM}$ ropivacaine $(p=0.003$, Figure $6 \mathrm{Cii})$. Neither incubation of cells with different concentrations of ropivacaine alone $(p=0.411)$ nor with LPS $(p=1)$ significantly altered total $\mathrm{Cav}-1$ expression compared to untreated cells (Figure 6Ciii).

\section{Active Src is required for endotoxin-induced increase in ICAM-1 expression}

To evaluate whether Src activation is required for the observed increase in ICAM-1 expression induced by LPS, we incubated HLMVEC with LPS in absence or presence of Src kinase inhibitor PP2 shown previously to effectively block Src activation [13] (Figure 7A). Densitometry analysis $(n=6)$ confirmed that LPS induced a 139\% increase in ICAM-1 expression compared to cells treated with vehicle alone (DMSO). PP2 blocked the LPS-induced increase in ICAM-1 expression by $79 \%$ $(p=0.005)$, but had no effect on ICAM-1 expression in absence of LPS ( $p=1$; Figure 7B) indicating LPS-induced increase in ICAM-1 is mediated in part via Src signaling. 


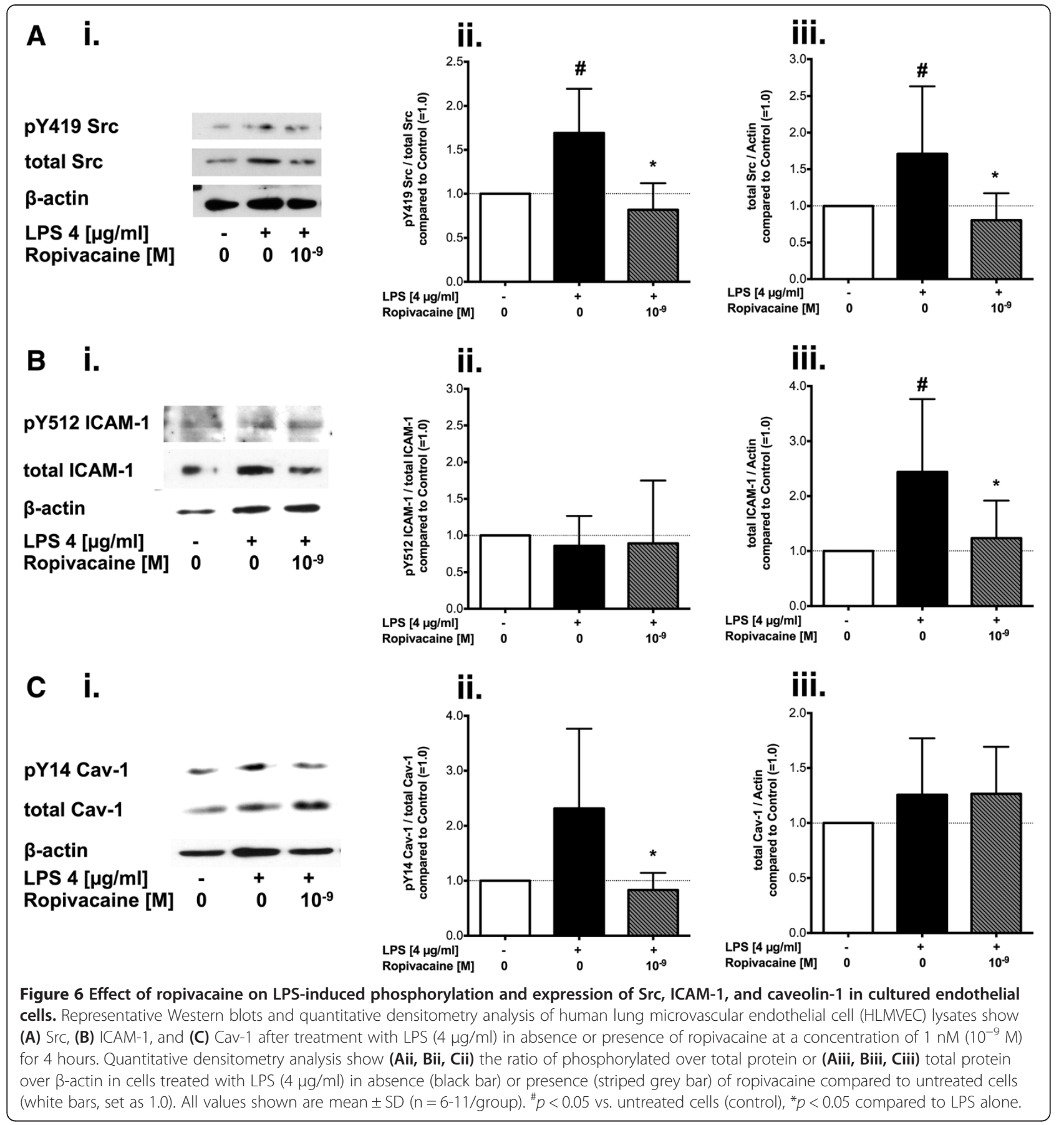

\section{Discussion}

The objective of this study was to determine the antiinflammatory mechanism of action of the local anesthetic ropivacaine using both in vivo and in vitro approaches. We assessed ALI induced by LPS exposure or HTV ventilation alone and in combination (i.e., "double-hit" model). The combination of the two stimuli increases the severity of ALI [6], most likely due to additive effects of mechanical injury and inflammatory cytokine signaling $[6,28]$.
The present study demonstrated that low-dose ropivacaine can attenuate ALI induced by LPS or the "doublehit" of LPS and HTV, but not by HTV ventilation alone. We also showed that this observed decrease might be due to an inhibition of LPS-induced Src activation/ expression, ICAM-1 expression, and Cav-1 phosphorylation. Our primary objective was to test the effect of the local anesthetic ropivacaine on HTV ventilation alone or HTV in combination with bacterial endotoxin as it was shown previously [9] that ALI induced by "high dose" LPS 


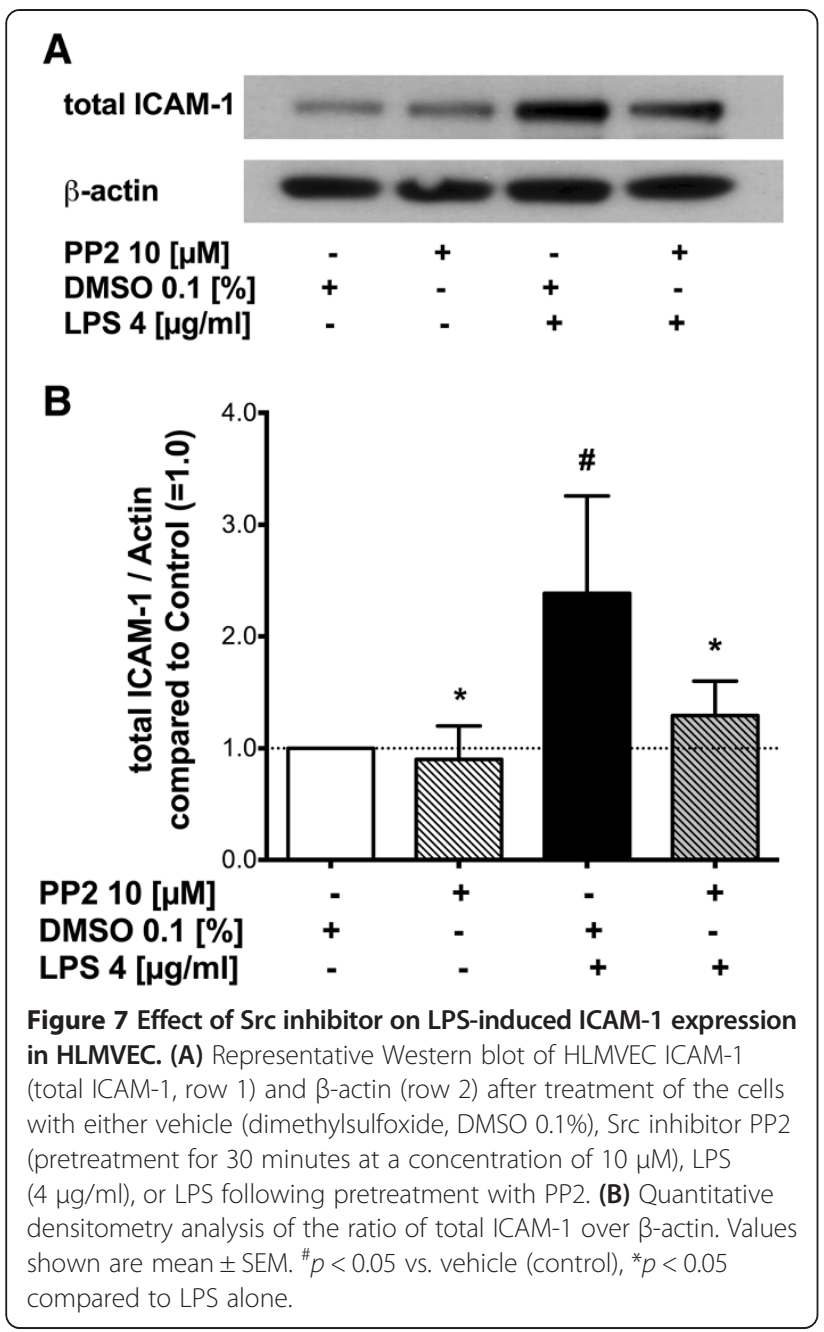

(delivered intraperitoneally or intratracheally) could be attenuated by ropivacaine. Changes in vascular permeability were rather small 4 hours after "low dose" LPS exposure, which were comparable to those induced by mechanical ventilation alone [6]. Thus, previous results were confirmed by our study.

The combination of two harmful stimuli, LPS and HTV ventilation, can exponentially increase the severity of ALI [6], most likely due to additive effects of mechanical injury and inflammatory cytokine signaling $[6,28]$, which may be relevant to mechanically-ventilated patients in the intensive care unit setting [29]. We observed a protective effect of ropivacaine only in animals treated with both stimuli or with LPS alone, whereas there was no effect of ropivacaine in animals challenged by HTV ventilation alone, indicating that ropivacaine selectively inhibits inflammatory signaling induced by LPS in in the lung - independent of ventilation.

The dose of intravenous ropivacaine used in our experimental setting $(0.33 \mathrm{mg} / \mathrm{kg}$ or $0.01 \mathrm{mg}$ for a $30 \mathrm{~g}$ mouse) was chosen based on previous experiments where this dose was shown to be effective in attenuating LPSinduced lung injury [9]. The conversion factor for determining what the ropivacaine dose in mice would equate to in humans is approximately 12:1 [30,31], which means our animal dose would be equivalent to a human dose of $0.027 \mathrm{mg} / \mathrm{kg}$, or a total of $1.89 \mathrm{mg}$ for a $70 \mathrm{~kg}$ patient. Mean (total) plasma concentration of ropivacaine of $1.82 \mathrm{mg} / \mathrm{l}(5.5 \mu \mathrm{M})$ has been reported to be present (and well-tolerated) in patients after continuous epidural infusions of $0.2 \%$ ropivacaine at a rate of $10 \mathrm{mg} /$ hour for 48 hours after major abdominal or urologic surgery [32], thus indicating the ropivacaine dose used in our study is clinically relevant. Additionally, the concentrations used in cell culture experiments were previously proven to have no effect on the viability of rat lung epithelial and endothelial cells [9] as well as human lung adenocarcinoma cells [26].

Multiple mechanisms facilitate the transition from the initial "barotrauma" due to high inspiratory pressures to the distinct "biotrauma" of VILI [33,34]. Cyclic stretch of the lung, as in HTV ventilation, leads to a severe physical injury [33], but at the same time induces inflammatory signaling locally in alveolar epithelial cells, macrophages, and neutrophils which together with the direct effect of stretch on the endothelium, leads to barrier disruption, pulmonary edema, and neutrophil infiltration into alveolae $[4,34]$. The results of the present study suggest that ropivacaine partially blocked inflammatory signaling induced by HTV ventilation, but not the physical injury to the lung induced by stretch. Although ventilator- and LPS-induced lung injury share common signaling pathways, e.g. Src-dependent caveolin-1 and ICAM-1 signaling $[6,13,19,20,25,35-38]$, the physical injury induced by HTV ventilation is much more severe and includes mechanical disruption of cell membranes and subsequent necrosis $[33,39]$. Presumably $60 \%$ of the injured cells are able to repair their membrane defects, a process that also involves inflammatory signaling via the $\mathrm{NFKB}$ pathway $[33,40]$. However, the severity and complexity of the stretchinduced injury might explain the differences observed between Western blots, where activation of inflammatory Src signaling in vivo and in vitro were shown to be attenuated by ropivacaine, and in vivo measures of ALI/VILI, where ropivacaine had no effect on VILI per se. Additionally, ropivacaine was applied intravenously through a central venous catheter and therefore the effects were primarily exerted on endothelial cells. Thus, subsequent in vitro experiments in this study using human lung microvascular endothelial cells focused on establishing a molecular mechanism by which ropivacaine exerts its protective effects by blocking the signaling events initiated by LPS.

Endothelial hyperpermeability due to barrier dysfunction of pulmonary capillaries is a key element of the pathogenesis of ALI and ARDS [1]. It was shown previously [9] 
that ALI induced by "high dose" LPS (delivered intraperitoneally or intratracheally) could be attenuated by ropivacaine. Our results indicated that ropivacaine was only able to attenuate ALI induced by HTV + LPS, having no effect on HTV alone. To gain novel mechanistic insight into the proposed anti-inflammatory properties of ropivacaine on inflammation-induced endothelial barrier dysfunction and lung edema [41], we assessed LPS-induced inflammatory Src, ICAM-1, and caveolin-1 (Cav-1) signaling in human lung microvascular endothelial cells (HLMVECs) in vitro. The observed inhibition of LPS-induced expression/activation of Src, ICAM-1, and Cav-1 in endothelial cells by ropivacaine provided significant insight into the possible anti-inflammatory mechanism and potential therapeutic benefit of amide-linked local anesthetics on the pathogenesis of ALI.

We, and others, have shown that Src protein tyrosine kinase $(\mathrm{Src})$ is a key regulator of endothelial barrier function. Src-dependent phosphorylation of ICAM-1 tyrosine 512 (human, tyrosine 518 in mice) increases neutrophil adhesion that can give rise to vascular inflammation [14] and Cav-1-dependent pulmonary vascular leakage [35]. Additionally, Src phosphorylation of vascular endothelial (VE-) cadherin on two distinct tyrosine residues (Y658 and Y685) is thought to regulate adherens junction stability, ultimately resulting in increased vascular permeability [42-44]. It was also demonstrated that ropivacaine and lidocaine inhibit inflammatory endothelial cell Src activation and signaling induced by TNF $\alpha$ by preventing the initial signaling step downstream of TNF receptor-1, thus preventing endothelial barrier disruption as well as neutrophil adhesion [45].

In the current study, we showed that low-dose ropivacaine (1 nM in vitro and $0.01 \mathrm{mg}$ in vivo) lead to a reduction in LPS-induced Src expression and activation. However, we did not observe a significant difference in LPS-induced Src activity in the animals challenged by both LPS and hyperinflation, but rather only in animals exposed to LPS alone. This might be explained by the fact that the total lung homogenate contains several cell types (epithelial, endothelial, smooth muscle, fibroblasts, macrophages etc.) and that each of these cell types may react differently to LPS, HTV ventilation (and the combination of the two), and ropivacaine in terms of Src activation.

ICAM-1, a cell surface glycoprotein belonging to the immunoglobulin superfamily of adhesion molecules, is expressed in several different cell types including lung endothelial [16] and epithelial cells [46]. ICAM-1 is required for firm adhesion of neutrophils to the endothelium and for initiation of transendothelial neutrophil migration during vascular and systemic inflammation [16]. Additional experiments with $I C A M-1^{-/-}$mice in the present study confirmed that LPS-induced ALI in animals ventilated with HTV is clearly ICAM-1-dependent, whereas the lung injury caused by HTV alone might (at least in part) be independent of ICAM-1 and reflect the physical cell damage caused by cyclic stretch $[33,39,40]$. LPS activation of toll-like receptor 4 [6] promotes the release of inflammatory cytokines which recruit neutrophils to vascular, interstitial, and alveolar spaces of the lung [47], thereby leading to inflammatory hyper-permeability via disruption of the endothelial barrier $[35,48]$.

Interestingly, this investigation also demonstrated that Src activation is required for the observed increase in ICAM-1 expression induced by LPS in endothelial cells. Pre-treatment of cells with the Src inhibitor PP2 significantly blocked the increase in ICAM-1 expression, and thus together with the known requirement of nuclear factor $\kappa \mathrm{B}(\mathrm{NF}-\mathrm{\kappa B})$ activation in the mechanism of LPSinduced increase in ICAM-1 expression [49], Src signaling also plays a primary role. Consistent with the hypothesis that Src signaling upstream of NF- $\mathrm{kB}$ mediates LPSinduced ICAM-1 expression, Src activation of NF-kB was demonstrated in macrophages stimulated with LPS [50] and in pancreatic acinar cells stimulated with caerulein [51].

Caveolin-1 is required for formation and trafficking of caveolae, the primary vesicular carrier and mechanism of transcellular macromolecule transport (e.g. albumin) through the vascular endothelial barrier [52,53]. Increasingly, evidence points to the role of Cav-1 and caveolaemediated transcellular albumin transport (transcytosis) in the pathogenesis of ALI in general [12,18-20,28,37,54] and VILI in particular [20], although it could also be shown that caveolin-1 deficient mice developed a more severe VILI than WT animals [22]. In line with the current study, we previously showed that Src phosphorylation of Cav-1 tyrosine 14 [12] contributes to the development of vascular hyperpermeability via paracellular and transcellular pathways [19]. Here, we demonstrated that the inflammatory signaling mechanisms that promote Cav-1 phosphorylation-dependent increase in transcellular as well as paracellular permeability during VILI $[20,55]$ were blocked by ropivacaine. We observed a reduction in both Src activation and Cav-1 phosphorylation induced by HTV ventilation in animals treated with ropivacaine, although this did not abolish HTV (alone) induced ALI/VILI.

\section{Conclusion}

Low dose ropivacaine attenuated ALI induced by LPS alone as well as in the "double-hit" mouse model induced by the combination of LPS and hyperinflation, whereas there was no effect of ropivacaine on VILI induced by HTV ventilation alone or on ALI induced by the doublehit protocol in $I C A M-1^{-/-}$mice. This protective effect of ropivacaine was associated with a decrease in LPS-induced 
Src activation, ICAM-1 expression, and caveolin-1 phosphorylation suggesting that ropivacaine may have significant therapeutic potential for treating pulmonary vascular inflammation and endothelial hyperpermeabilty, thus preventing or tempering the development of ALI.

\section{Competing interest}

The authors report no conflict of interest.

\section{Authors' contributions}

TP helped conceive the study, conducted experiments, analyzed the data, and wrote the manuscript; ROD helped with data analysis and wrote the manuscript, GH helped conceive the study and conducted experiments; $M C$ and $A Z C$ conducted experiments; EGV helped conceive the study and wrote the manuscript; $A B$ helped conceive the study and wrote the manuscript; DES helped conceive the study and wrote the manuscript; BBS helped conceive the study, performed data analysis, and wrote the manuscript; RDM conceived the study, analyzed data, and wrote the manuscript. The manuscript was read and approved by all the authors.

\section{Funding}

This work was supported in part by the Society of Cardiovascular Anesthesiologists Foundation/IARS Starter Grant (TP), European Society of Regional Anaesthesia \& Pain Medicine Research Grant (AB), and NIH NHLBI grants R01 HL071626 and P01 HL060678 (RDM), and R01 HL104092 (GH). Received from the Department of Anesthesiology, University of Illinois at Chicago.

\section{Author details}

${ }^{1}$ Department of Anesthesiology, University of Illinois Hospital \& Health Sciences System, 835 S. Wolcott Ave (m/c 868), Chicago, IL 60612, USA. ${ }^{2}$ Department of Pharmacology, University of Illinois Hospital \& Health Sciences System, Chicago, IL, USA. ${ }^{3}$ Department of Bioengineering, University of Illinois Hospital \& Health Sciences System, Chicago, IL, USA. ${ }^{4}$ Center for Lung and Vascular Biology, University of Illinois Hospital \& Health Sciences System, Chicago, IL, USA. ${ }^{5}$ Institute of Anesthesiology, University Hospital Zurich, Zurich, Switzerland. ${ }^{6}$ Department of Anesthesiology, Balgrist University Hospital, Zurich, Switzerland. ${ }^{7}$ Department of Anesthesiology, Jesse Brown VA Medical Center, Chicago, IL, USA.

\section{Received: 15 November 2013 Accepted: 8 July 2014}

Published: 19 July 2014

\section{References}

1. Matthay MA, Ware LB, Zimmerman GA: The acute respiratory distress syndrome. J Clin Invest 2012, 122(8):2731-2740.

2. Matthay MA, Zemans RL: The Acute Respiratory Distress Syndrome: Pathogenesis and Treatment. Annu Rev Pathol 2011, 6:147-163.

3. Johnson ER, Matthay MA: Acute lung injury: epidemiology, pathogenesis, and treatment. J Aerosol Med Pulm Drug Deliv 2010, 23(4):243-252.

4. Frank JA, Matthay MA: Science review: mechanisms of ventilator-induced injury. Crit Care 2003, 7(3):233-241.

5. Ricard JD, Dreyfuss D, Saumon G: Ventilator-induced lung injury. Eur Respir J Suppl 2003, 42:2s-9s.

6. Hu G, Malik AB, Minshall RD: Toll-like receptor 4 mediates neutrophil sequestration and lung injury induced by endotoxin and hyperinflation. Crit Care Med 2010, 38(1):194-201.

7. Rosenberg PH: Future of regional anaesthesia. Acta Anaesthesiol Scand 2005, 49(7):913-918.

8. Costantini R, Affaitati G, Fabrizio A, Giamberardino MA: Controlling pain in the post-operative setting. Int I Clin Pharmacol Ther 2011, 49(2):116-127.

9. Blumenthal S, Borgeat A, Pasch T, Reyes L, Booy C, Lambert M, Schimmer RC, Beck-Schimmer B: Ropivacaine decreases inflammation in experimental endotoxin-induced lung injury. Anesthesiology 2006, 104(5):961-969.

10. De Klaver MJ, Buckingham MG, Rich GF: Lidocaine attenuates cytokineinduced cell injury in endothelial and vascular smooth muscle cells. Anesth Analg 2003, 97(2):465-470. table of contents.

11. De Klaver MJ, Weingart GS, Obrig TG, Rich GF: Local anesthetic-induced protection against lipopolysaccharide-induced injury in endothelial cells: the role of mitochondrial adenosine triphosphate-sensitive potassium channels. Anesth Analg 2006, 102(4):1108-1113.

12. $\mathrm{Hu} G$, Minshall RD: Regulation of transendothelial permeability by Src kinase. Microvasc Res 2009, 77(1):21-25.

13. Liu G, Place AT, Chen Z, Brovkovych VM, Vogel SM, Muller WA, Skidgel RA, Malik AB, Minshall RD: ICAM-1-activated Src and eNOS signaling increase endothelial cell surface PECAM-1 adhesivity and neutrophil transmigration. Blood 2012, 120(9):1942-1952.

14. Liu G, Vogel SM, Gao X, Javaid K, Hu G, Danilov SM, Malik AB, Minshall RD: Src phosphorylation of endothelial cell surface intercellular adhesion molecule-1 mediates neutrophil adhesion and contributes to the mechanism of lung inflammation. Arterioscler Thromb Vasc Biol 2011, 31(6):1342-1350.

15. Beck-Schimmer B, Schimmer RC, Warner RL, Schmal H, Nordblom G, Flory CM, Lesch ME, Friedl HP, Schrier DJ, Ward PA: Expression of lung vascular and airway ICAM-1 after exposure to bacterial lipopolysaccharide. Am J Respir Cell Mol Biol 1997, 17(3):344-352.

16. Muller WA: Mechanisms of leukocyte transendothelial migration. Annu Rev Pathol 2011, 6:323-344.

17. Boscher C, Nabi IR: Caveolin-1: role in cell signaling. Adv Exp Med Biol 2012, 729:29-50.

18. Kronstein R, Seebach J, Grossklaus S, Minten C, Engelhardt B, Drab M, Liebner S, Arsenijevic Y, Taha AA, Afanasieva T, Schnittler HJ: Caveolin-1 opens endothelial cell junctions by targeting catenins. Cardiovasc Res 2012, 93(1):130-140.

19. Sun Y, Hu G, Zhang X, Minshall RD: Phosphorylation of caveolin-1 regulates oxidant-induced pulmonary vascular permeability via paracellular and transcellular pathways. Circ Res 2009, 105(7):676-685. 615 p following 685.

20. Maniatis NA, Kardara M, Hecimovich D, Letsiou E, Castellon M, Roussos C, Shinin V, Votta-Vellis EG, Schwartz DE, Minshall RD: Role of caveolin-1 expression in the pathogenesis of pulmonary edema in ventilator-induced lung injury. Pulm Circ 2012, 2(4):452-460.

21. Ngiam N, Peltekova V, Engelberts D, Otulakowski G, Post M, Kavanagh BP: Early growth response-1 worsens ventilator-induced lung injury by up-regulating prostanoid synthesis. Am J Respir Crit Care Med 2010, 181(9):947-956.

22. Hoetzel A, Schmidt R, Vallbracht S, Goebel U, Dolinay T, Kim HP, Ifedigbo E, Ryter SW, Choi AM: Carbon monoxide prevents ventilator-induced lung injury via caveolin-1. Crit Care Med 2009, 37(5):1708-1715.

23. Hegeman MA, Hennus MP, Cobelens PM, Kavelaars A, Jansen NJ, Schultz MJ, Van Vught AJ, Heijnen CJ: Dexamethasone attenuates VEGF expression and inflammation but not barrier dysfunction in a murine model of ventilator-induced lung injury. PLoS One 2013, 8(2):e57374.

24. Su X, Lee JW, Matthay ZA, Mednick G, Uchida T, Fang X, Gupta N, Matthay MA: Activation of the alpha7 $\mathrm{nAChR}$ reduces acid-induced acute lung injury in mice and rats. Am J Respir Cell Mol Biol 2007, 37(2):186-192.

25. Hu G, Ye RD, Dinauer MC, Malik AB, Minshall RD: Neutrophil caveolin-1 expression contributes to mechanism of lung inflammation and injury. Am J Physiol Lung Cell Mol Physiol 2008, 294(2):L178-L186.

26. Piegeler T, Votta-Velis EG, Liu G, Place AT, Schwartz DE, Beck-Schimmer B, Minshall RD, Borgeat A: Antimetastatic Potential of Amide-linked Local Anesthetics: Inhibition of Lung Adenocarcinoma Cell Migration and Inflammatory Src Signaling Independent of Sodium Channel Blockade. Anesthesiology 2012, 117(3):548-559.

27. Place AT, Chen Z, Bakhshi FR, Liu G, O'Bryan JP, Minshall RD: Cooperative role of caveolin-1 and C-terminal Src kinase binding protein in $\mathrm{C}$-terminal Src kinase-mediated negative regulation of c-Src. Mol Pharmacol 2011, 80(4):665-672.

28. Altemeier WA, Matute-Bello G, Frevert CW, Kawata Y, Kajikawa O, Martin TR, Glenny RW: Mechanical ventilation with moderate tidal volumes synergistically increases lung cytokine response to systemic endotoxin. Am J Physiol Lung Cell Mol Physiol 2004, 287(3):L533-L542.

29. Altemeier WA, Matute-Bello G, Gharib SA, Glenny RW, Martin TR, Liles WC: Modulation of lipopolysaccharide-induced gene transcription and promotion of lung injury by mechanical ventilation. J Immunol 2005, 175(5):3369-3376.

30. Freireich EJ, Gehan EA, Rall DP, Schmidt LH, Skipper HE: Quantitative comparison of toxicity of anticancer agents in mouse, rat, hamster, dog, monkey, and man. Cancer Chemother Rep 1966, 50(4):219-244.

31. Reagan-Shaw S, Nihal M, Ahmad N: Dose translation from animal to human studies revisited. FASEB J 2008, 22(3):659-661.

32. Cusato M, Allegri M, Niebel T, Ingelmo P, Broglia M, Braschi A, Regazzi M: Flip-flop kinetics of ropivacaine during continuous epidural infusion influences its accumulation rate. Eur J Clin Pharmacol 2011, 67(4):399-406. 
33. Plataki M, Hubmayr RD: The physical basis of ventilator-induced lung injury. Expert Rev Respir Med 2010, 4(3):373-385.

34. Slutsky AS: Ventilator-induced lung injury: from barotrauma to biotrauma. Respir Care 2005, 50(5):646-659.

35. Hu G, Vogel SM, Schwartz DE, Malik AB, Minshall RD: Intercellular adhesion molecule-1-dependent neutrophil adhesion to endothelial cells induces caveolae-mediated pulmonary vascular hyperpermeability. Circ Res 2008, 102(12):e120-e131.

36. Jiao H, Zhang Y, Yan Z, Wang ZG, Liu G, Minshall RD, Malik AB, Hu G: Caveolin-1 Tyr14 phosphorylation induces interaction with TLR4 in endothelial cells and mediates MyD88-dependent signaling and sepsis-induced lung inflammation. J Immunol 2013, 191(12):6191-6199.

37. Jin Y, Lee SJ, Minshall RD, Choi AM: Caveolin-1: a critical regulator of lung injury. Am J Physiol Lung Cell Mol Physiol 2011, 300(2):L151-L160.

38. Liu D, Yan Z, Minshall RD, Schwartz DE, Chen Y, Hu G: Activation of calpains mediates early lung neutrophilic inflammation in ventilatorinduced lung injury. Am J Physiol Lung Cell Mol Physiol 2012, 302(4):L370-L379.

39. Vlahakis NE, Hubmayr RD: Cellular stress failure in ventilator-injured lungs. Am J Respir Crit Care Med 2005, 171(12):1328-1342.

40. Gajic O, Lee J, Doerr CH, Berrios JC, Myers JL, Hubmayr RD: Ventilatorinduced cell wounding and repair in the intact lung. Am J Respir Crit Care Med 2003, 167(8):1057-1063.

41. Bhattacharya J, Matthay MA: Regulation and repair of the alveolarcapillary barrier in acute lung injury. Annu Rev Physiol 2013, 75:593-615.

42. Dejana E, Giampietro C: Vascular endothelial-cadherin and vascular stability. Curr Opin Hematol 2012, 19(3):218-223.

43. Dejana E, Orsenigo F, Lampugnani MG: The role of adherens junctions and VE-cadherin in the control of vascular permeability. J Cell Sci 2008, 121(Pt 13):2115-2122.

44. Orsenigo F, Giampietro C, Ferrari A, Corada M, Galaup A, Sigismund S, Ristagno G, Maddaluno L, Koh GY, Franco D, Kurtcuoglu V, Poulikakos D, Baluk P, McDonald D, Grazia Lampugnani M, Dejana E: Phosphorylation of VE-cadherin is modulated by haemodynamic forces and contributes to the regulation of vascular permeability in vivo. Nat Commun 2012, 3:1208.

45. Piegeler T, Votta-Velis EG, Bakhshi FR, Mao M, Carnegie G, Bonini MG, Schwartz DE, Borgeat A, Beck-Schimmer B, Minshall RD: Endothelial barrier protection by local anesthetics: ropivacaine and lidocaine block tumor necrosis factor-alpha-induced endothelial cell Src activation. Anesthesiology 2014, 120(6):1414-1428.

46. Beck-Schimmer B, Schimmer RC, Schmal H, Flory CM, Friedl HP, Pasch T, Ward PA: Characterization of rat lung ICAM-1. Inflamm Res 1998, 47(7):308-315.

47. Beck-Schimmer B, Madjdpour C, Kneller S, Ziegler U, Pasch T, Wuthrich RP, Ward PA, Schimmer RC: Role of alveolar epithelial ICAM-1 in lipopolysaccharide-induced lung inflammation. Eur Respir J 2002, 19(6):1142-1150

48. Daniel AE, Van Buul JD: Endothelial Junction Regulation: A Prerequisite for Leukocytes Crossing the Vessel Wall. J Innate Immun 2013, 5(4):324-335.

49. Cho YS, Kim CH, Ha TS, Lee SJ, Ahn HY: Ginsenoside rg2 inhibits lipopolysaccharide-induced adhesion molecule expression in human umbilical vein endothelial cell. Korean J Physiol Pharmacol 2013, 17(2):133-137.

50. Kang JL, Lee HW, Kim HJ, Lee HS, Castranova V, Lim CM, Koh Y: Inhibition of SRC tyrosine kinases suppresses activation of nuclear factor-kappaB, and serine and tyrosine phosphorylation of IkappaB-alpha in lipopolysaccharide-stimulated raw 264.7 macrophages. J Toxicol Environ Health A 2005, 68(19):1643-1662.

51. Tamizhselvi R, Koh YH, Sun J, Zhang H, Bhatia M: Hydrogen sulfide induces ICAM-1 expression and neutrophil adhesion to caerulein-treated pancreatic acinar cells through NF-kappaB and Src-family kinases pathway. Exp Cell Res 2010, 316(9):1625-1636.

52. Cohen AW, Hnasko R, Schubert W, Lisanti MP: Role of caveolae and caveolins in health and disease. Physiol Rev 2004, 84(4):1341-1379.

53. Minshall RD, Tiruppathi C, Vogel SM, Malik AB: Vesicle formation and trafficking in endothelial cells and regulation of endothelial barrier function. Histochem Cell Biol 2002, 117(2):105-112.
54. Maniatis NA, Chernaya O, Shinin V, Minshall RD: Caveolins and lung function. Adv Exp Med Biol 2012, 729:157-179.

55. Maniatis NA, Shinin V, Schraufnagel DE, Okada S, Vogel SM, Malik AB, Minshall RD: Increased pulmonary vascular resistance and defective pulmonary artery filling in caveolin-1-/- mice. Am J Physiol Lung Cell Mol Physiol 2008, 294(5):L865-L873.

doi:10.1186/1471-2253-14-57

Cite this article as: Piegeler et al:: Ropivacaine attenuates endotoxin plus hyperinflation-mediated acute lung injury via inhibition of early-onset Src-dependent signaling. BMC Anesthesiology 2014 14:57.

\section{Submit your next manuscript to BioMed Central and take full advantage of:}

- Convenient online submission

- Thorough peer review

- No space constraints or color figure charges

- Immediate publication on acceptance

- Inclusion in PubMed, CAS, Scopus and Google Scholar

- Research which is freely available for redistribution

Submit your manuscript at www.biomedcentral.com/submit
C) BioMed Central 